\title{
Knowledge, perception, and dengue prevention behavior in lowokwaru sub district, urban area in Malang, Indonesia
}

\author{
Alidha Nur Rakhmani ${ }^{1 *}$, Kamolnetr Okanurak ${ }^{2}$, Jaranit Kaewkungwal ${ }^{3}$, Yanin Limpanont ${ }^{4}$, \\ Sopon Iamsirithaworn ${ }^{5}$ \\ ${ }^{1}$ Faculty of Medicine, Brawijaya University Malang, Indonesia \\ 2,3,4 Tropical Medicine, Mahidol University, Thailand \\ ${ }^{5}$ Ministry of Public Health Thailand
}

\section{Key Words: \\ Dengue \\ Prevention \\ Behavior \\ Urban \\ Malang}

Indonesia

Received: 28 September 2016

Accepted: 28 October 2016

Published: 13 February 2017

\begin{abstract}
One strategy to control dengue in Indonesia is changing behavior practice using the slogan 3M plus. 3M consists of cleaning water containers, covering water containers, and burying or throwing discarded items. Plus is activity to avoid mosquito bite (using repellent or long sleeves) and reduce mosquito breeding, such as fog. This study aimed to determine the level of knowledge, perception, and prevention behavior regarding dengue in the Lowokwaru sub-district, an urban area in Malang, Indonesia. A crosssectional study using a semi-structured questionnaire among 220 respondents was conducted by face-toface interview. More than 43 percent (43.6\%) of respondents exhibited a moderate level of knowledge. They had good knowledge regarding the cause and severity of dengue. However, they had low knowledge about prevention actions. Most of the respondents had a positive perception of dengue. The positive perception was found towards susceptibility and severity of dengue and only moderate perception towards prevention actions. Most of them (61\%) were more likely to perform 3M prevention behavior than plus prevention behavior. Respondents had low knowledge and needed an improved practice level regarding prevention actions, particularly plus prevention activities. Therefore, this study suggests that the $3 \mathrm{M}$ plus campaign should provide more information about prevention behavior knowledge than plus activities.
\end{abstract}

(C) 2017 The Author(s). Published by TAF Publishing.

\section{INTRODUCTION}

First dengue cases were reported in Jakarta (DKI Jakarta) and Surabaya (East Java) in 1964. At that time, there were 58 dengue patients among whom 24 persons died in Surabaya. Thereafter, the incidence and prevalence of dengue widely spread in all provinces throughout Indonesia[1, 2]. By 2010, Indonesia ranked as the highest of dengue cases in Southeast Asian Nations [3]. In 2014, Ministry of Health of Indonesia reported that the highest dengue cases were found in West Java, Central Java, and East Java [4]. Dengue is health problem in Malang, the second largest city of East Java Province in Indonesia. The number of dengue cases reported was highest in 2010 in Malang. Total of 658 dengue cases were found during January to May in that year. The number of cases decreased year by

\footnotetext{
${ }^{*}$ Corresponding author: Alidha Nur Rakhmani

†Email: alidha_nur@yahoo.com
} 
year thereafter. However, in 2014, the number of cases began to increase. There were 160 dengue patients with one patient facing death in urban area in the year 2014. In 2015, 181 dengue patients with three mortality cases occured during January to December $[5,6]$. Data showed that dengue cases were higher in urban than in rural area. It was supported by surveillance study in Malang in the year 2010 that identified urban areas had mosquito larvae more than rural areas [7]. In 1992, the Ministry of Health launched strategies including surveillance systems, case management, control vector, and changing people's behavior. Vector control and changing people's behavior are combined through surveillance system. This program is known as $3 \mathrm{M}$ plus, meaning to combat mosquito nest that should be carried out periodically by the community. $3 \mathrm{M}$ is composed of three Ms: menutup (covering the water container), menguras (cleaning the water container), and mengubur/membuang (burying/throwing discarded items). Plus are activities to reduce mosquito breeding places such as using chemical to kill larva or fogging. Plus can also be described as activities to protect people from mosquito bite for example using repellent, mosquito coils, larvasida, or long sleeves and trouser $[1,8]$. Previous studies investigated that many factors influence practice of dengue prevention such as knowledge and perception. They reported that participants with higher knowledge of dengue reported higher prevention behavior than those with low knowledge $[9,14]$. In addition, studies found that individuals with higher perceived susceptibility of acquiring dengue had higher dengue prevention behavior $[9,10]$. A study in Malaysia showed that the prevalence of dengue fever was higher in participants who practiced high risk behaviour as compared to those who practiced low risk behaviour [14]. Investigators in Laos revealed that persons with good knowledge were more likely to have good preventive behavior compared with those with poor knowledge $[11,15]$. However, several studies revealed that good knowledge about dengue fever among community did not translate into adopting good preventive practice [16-18]. Despite evidence up to now, changing behavior may solve dengue problem in most countries. Many previous studies reported dengue prevention behavior in many places. However, there is no report on dengue prevention behavior in Malang, therefore this study aimed at investigating level of knowledge, perception, and dengue prevention behaviors in urban areas in Malang, Indonesia.

\section{RESEARCH METHOD}

\section{Study Design and Sample}

This was a cross-sectional study. Study was conducted among respondents who lived in Lowokwaru village, Lowokwaru sub district, East Java during May - June 2016. This study enrolled Malang residents aged 18 years and above, registered, lived more than 6 months in urban areas in Malang, and were willing to participate in this study. Residents who were not at home during data collection were excluded from this study. The minimum sample size was 191 [19] and afterwards added 20\% for anticipating non-response rate, therefore this study collected data from 220 respondents. Quota sampling was used to select one respondent in each house from 15 clusters.

\section{Data Collection and Analysis}

Data collection to explore knowledge, perception, and dengue prevention behavior used semi-structured questionnaire by face-to-face interview. The total score of knowledge was 14 and respondents would be considered at need improvement level if the scores $<60 \%$ $=0-8$, moderate level if scores $60 \%-80 \%=9-11$, and good level of knowledge if the scores $=12-14$. Perception part consisted of 19 statements. Each positive statement was given 
score 5 for strongly agree, 4 for agree, 3 for neutral, 2 for disagree, and 1 for strongly disagree. Conversely score had been given for negative statements, score 5 for strongly disagree, 4 for disagree, 3 for neutral, 2 for agree, and 1 for strongly agree. Total score was 95 and categorized into negative perception if the score ranged from 0-31, moderate preception if the score ranged from 32-63, and positive perception if the score ranged from 64-95. The total score of dengue prevention behavior was 18 and participants had been considered at need improvement level if they get the score $<60 \%=0-10$, moderate level if get score $60 \%-80 \%=11-14$, and good level of prevention behavior if the score $=15-18$. SPSS was used to analyze and descriptive data were presented by frequency and percentage.

\section{Ethical Consideration}

This study was approved by the Ethics Committee of the Faculty of Tropical Medicine, Mahidol University (MUTM 2016-015-01) and local Ethics Committee in Malang, Indonesia (196 / EC / KEPK / S2 / 05 / 2016).

\section{RESULTS}

\section{Socio Demographic Factors}

Majority of respondents were female, average age was 45 years, were housewife, had low educational background, and average income 1-3 million rupiah per month. More than 21 percent (21.4\%) of respondents had been living in Malang for 31-40 years. Mostly respondents had 3-4 family members in their house (Table 1). Almost 90 percent (87.7\%) of respondents mentioned that they obtained information about dengue, while 12.3 percent of them did not have. More than 32 percent $(32.4 \%)$ of respondents who had dengue information said that the main resource of information was television (Table 2).

TABLE 1. Participant's socio-demographic

\begin{tabular}{|c|c|c|}
\hline Characteristic & $\mathbf{N}$ & $\%$ \\
\hline \multicolumn{3}{|l|}{ Gender } \\
\hline Male & 60 & 27.3 \\
\hline Female & 160 & 72.7 \\
\hline Age & \multicolumn{2}{|l|}{ Mean (SD) $44.94 \pm 14.037$} \\
\hline $18-30$ & 40 & 18.2 \\
\hline $31-40$ & 48 & 21.8 \\
\hline $41-50$ & 49 & 22.3 \\
\hline $51-60$ & 52 & 23.6 \\
\hline$>60$ & 31 & 14.1 \\
\hline Duration of stay in Malang & \multicolumn{2}{|l|}{ Mean (SD) $36.89 \pm 18.277$} \\
\hline$<21$ years & 44 & 20 \\
\hline $21-30$ years & 32 & 14.5 \\
\hline $31-40$ years & 47 & 21.4 \\
\hline $41-50$ years & 41 & 18.6 \\
\hline $51-60$ years & 35 & 15.9 \\
\hline$>60$ years & 21 & 9.5 \\
\hline \multicolumn{3}{|l|}{ Education } \\
\hline No education & 2 & 0.9 \\
\hline Elementary & 23 & 10.5 \\
\hline Junior high school & 33 & 15.0 \\
\hline Senior high school & 110 & 50.0 \\
\hline $13-15$ years education & 7 & 3.2 \\
\hline University and higher & 45 & 20.5 \\
\hline \multicolumn{3}{|l|}{ Occupation } \\
\hline Unemployed & 126 & 57.3 \\
\hline Government & 6 & 2.7 \\
\hline Private (owner) & 31 & 14.1 \\
\hline Private (worker) & 57 & 25.9 \\
\hline \multicolumn{3}{|l|}{ Income/month } \\
\hline$<1$ million rupiah $(<100$ USD) & 18 & 19.1 \\
\hline 1-3 million rupiah (100-300 USD) & 63 & 67.0 \\
\hline$>3$ million rupiah (> 300 USD) & 13 & 13.8 \\
\hline \multicolumn{3}{|l|}{ Number of family } \\
\hline 1-2 persons & 22 & 10.1 \\
\hline 3-4 persons & 99 & 45.4 \\
\hline$>4$ persons & 97 & 44.5 \\
\hline
\end{tabular}


TABLE 2 . Dengue information

\begin{tabular}{lcc}
\hline \hline Description & $\mathbf{N}$ & $\mathbf{\%}$ \\
\hline Having information of dengue & & \\
Yes & 193 & 87.7 \\
No & 27 & 12.3 \\
Resource & & \\
Family & 31 & 10.6 \\
Friend & 33 & 11.3 \\
Local primary health care & 72 & 24.6 \\
TV & 95 & 32.4 \\
Other & 62 & 21.2 \\
\hline \hline
\end{tabular}

\section{Knowledge}

This study revealed that 43.6 percent of respondents had moderate level of knowledge. Respondents had good knowledge regarding cause of dengue and severity of dengue. More than 80 percent of them answered the cause of dengue correctly. In addition, more than 96 percent of respondents showed good knowledge either in terms of dengue could cause death $(96.4 \%)$ and be prevented $(98.2 \%)$. Although almost all respondents mentioned that they could prevent dengue, 60.9 percent of them achieved moderate level of knowledge about prevention activities (Table 3). Respondents showed low level of knowledge about the highest season of dengue infection, age group of people getting sick of dengue, symptoms of dengue, and personal protection. Less than 53 percent of them $(52.1 \%)$ correctly pointed out the person who would get sick of dengue. Only 56.8 percent and 31.4 percent of respondents could answer symptoms of dengue and personal protection respectively. Several respondents mentioned dry season as the highest season of dengue infection. Few respondents mentioned that only children or teenagers could get infected by dengue. For the symptoms, all respondents who knew the symptoms mentioned fever as one of three most common symptoms. Only 31.4 percent of respondents could correctly answer personal protection activity (Table 3).

TABLE 3 . Knowledge of dengue and dengue prevention behavior among 220 respondents in Lowokwaru sub district in Malang

\begin{tabular}{lcc}
\hline \multicolumn{3}{c}{ Nespondents in Lowokwaru sub district in Malang } \\
\hline \hline Variables & Number & \% \\
\hline Knowledge level overall & 130 & 43.6 \\
the highest season of dengue infection & $59.1]$ \\
Group age of people who can get sick of dengue & 116 & 52.7 \\
The cause of dengue & 180 & 81.8 \\
3 mostly common symptom of dengue & 125 & 56.8 \\
Dengue could makes patient died & 212 & 96.4 \\
We can prevent dengue infection & 216 & 98.2 \\
3 activities that can prevent dengue & 134 & 60.9 \\
one activity of personal protection & 69 & 31.4 \\
\hline \hline$<6 \%$ = need improvement 60-80\% = moderate > 80\% = good & &
\end{tabular}

\section{Perception}

This study found 82.3 percent of respondents had moderate perception and 17.7 percent of them had positive perception. Respondents had positive perception regarding susceptibility and severity. More than 76 percent of them (76.4\%) had positive perception con- 
cerning benefit of dengue prevention behavior. However it was found that they had moderate perception toward barrier of dengue prevention behavior approximately 53.2 percent (Table 4).

TABLE 4 . Perception level of dengue and dengue prevention behavior among 218 respondents in Lowokwaru sub district, Malang

\begin{tabular}{lccc}
\hline \hline Issue & Mean score \pm SD & \multicolumn{2}{c}{ Perception Level } \\
& & Moderate (\%) & Positive (\%) \\
\hline Susceptibility & $12.14 \pm 1.63$ & $32(14.5)$ & $188(85.5)$ \\
Severity & $12.39 \pm 1.67$ & $33(15)$ & $187(85)$ \\
Benefit of dengue prevention behavior & $18.80 \pm 3.19$ & $52(23.6)$ & $168(76.4)$ \\
Barrier of dengue prevention behavior & $27.10 \pm 4.83$ & $117(53.2)$ & $103(46.8)$ \\
Perception level overall & $70.43 \pm 8.85$ & $39(17.7)$ & $181(82.3)$ \\
\hline \hline
\end{tabular}

\section{Dengue Prevention Behavior}

About 61 percent of them practiced moderate behavior. The study revealed that $3 \mathrm{M}$ were the most behavior done. Around 84 percent of them (83.5\%) covered water container. Almost 75 percent of them $(74.8 \%)$ cleaned water container in the bathroom at least once a week and more than 1 time / week. In contrast, the percentage of respondents who practiced plus activities such as used repellent and mosquito coils properly at daytime were only 17 percent and 8.7 percent respectively. Furthermore, more than 59 percent of them (59.2\%) never used repellent and $37.6 \%$ of respondents never used mosquito coils. About 165 respondents or 75.7 percent did not put abate into water container (Table 5).

TABLE 5 . Prevention behavior among 218 respondents in Lowokwaru

\begin{tabular}{lcc}
\multicolumn{1}{c}{ sub district, Malang } & N & \% \\
\hline \hline Behavior & 78 & 35.8 \\
\hline Behavior level overall & 133 & 61 \\
Need improvement & 7 & 3.2 \\
Moderate & & \\
Good & 163 & 74.8 \\
Practice of behavior & 66 & 83.5 \\
Cleaning water container in bathroom $\geq 1$ x /week & 19 & 65.5 \\
Have water container inside and always cover & 129 & 59.2 \\
Have water container outside and always cover & 82 & 37.6 \\
Throw discarded items $\leq 1$ week & 129 & 59.2 \\
Never used mosquito coils & 165 & 75.7 \\
Never used repellent & 178 & 81.7 \\
Don't put abate & 170 & 78.0 \\
Sometime wear long sleeves at day time & & \\
Sometime wear long pants / skirts at day time & & \\
\hline \hline
\end{tabular}

\section{DISCUSSION}

\section{Knowledge}

This study revealed that 43.6 percent of respondents had knowledge at moderate level and another 36.4 percent had good level of knowledge. This was similar to studies conducted among Myanmar migrants that revealed average of respondents had moderate level of 
knowledge [20,21]. This condition might be because majority of respondents obtained information about dengue from primary health care provider or health promotion very often due to endemic region in Indonesia. This study found that more than 90 percent of respondents had information about dengue. They received information mostly from local primary health provider and television. This was consistent with several studies that reported TV as the main source of dengue information $[12,16,18]$. The Ministry of Health had given campaign on dengue prevention behavior by advertising on social media and television. In addition, primary health care provider collaborated with health volunteer and working woman group in each cluster actively provided health promotion about dengue.

This study found 80 percent of respondents had moderate and good level of knowledge, however only 3.2 percent respondents who performed good level of dengue prevention behavior. Similar to a cross-sectional study in Bali that found 95.6 percent respondents had level of good knowledge and only 51.1 percent practiced good level of behavior [22]. Regarding the knowledge, several respondents mentioned that dry season is the highest season of dengue infection. They argued that more mosquitoes lived in dry season. This opinion might be expressed due to uncertainty of the season change in Malang. Few years ago, the change of temperature was in accordance with the season. The weather was cold during dry season, however at present the weather was hot during dry season. Thus, it could increase mosquito population during dry season.

About 47.3 percent of respondents who incorrectly answered age group of getting sick of dengue mentioned that only young children, teenagers, or young adults could get dengue. They were not aware that infants and elderly people could also get dengue. It might be because mostly dengue cases were reported in young children or teenagers. However, respondents who correctly answered the question revealed that nowadays dengue could attack all age. During data collection, few respondents found dengue cases in elderly people in their neighbour. Previous study revealed that 85.6 percent of respondents had known mosquito as vector [23]. This study found around 82 percent of respondents $(81.8 \%)$ mentioning the mosquito bite as route of dengue transmission, although most of them did know the name of mosquito. However, some respondents said Aedes aegypti is the mosquito that transmitted dengue. About 18.2 percent of them said that poor environment with much puddle could cause dengue. Around 57 percent of respondents (56.8\%) correctly answered symptoms of dengue. They mentioned fever as the main symptom followed by rash on the skin. This result was similar to the study in Malaysia [24]. Although almost all respondents (98.2\%) mentioned that they could prevent dengue, only 60.9 percent of them could correctly answer three dengue prevention activities. Almost 40 percent of them (39.1\%) mentioned one or two dengue prevention activities. Cleaning water container in the bathroom was most often the answer. Personal activity was part of plus activities from dengue prevention actions. The average of knowledge was low for prevention. This was different from the study in Thailand which reported knowledge about dengue prevention behavior was better than others [20]. This study found only 69 persons (31.4\%) correctly identifying personal activity. However, they could explain about repellent, mosquito coils, or long clothes. This might be because they were not familiar with the term protection activity, although some of them practiced it.

\section{Perception}

Considering respondent's perception, none of them had negative perception. This study found that 17.7 percent of them achieved moderate level of perception and 82.3 percent 
of them achieved positive level of perception. Compared to studies in Laos [15] and Aceh [25], respondents in this study had higher perception. However, study in Aceh found that generally practiced dengue prevention behavior was on need improvement $[25,28]$ while this study reported respondents practiced moderate level of dengue prevention behavior. In general, this study revealed positive perception concerning susceptibility and severity. More than 90 percent of respondents strongly agreed (32.7\%) and agreed (60\%) that everyone could get sick of dengue. They also had positive perception regarding children getting sick of dengue easier than adults and persons experienced with dengue could get infected again. This perception might be the reason for practicing moderate and good prevention activities. A previous study in Malaysia also found that respondents with higher susceptibility perception had a higher dengue prevention behavior [10].

More than 90 percent of respondents had positive perception regarding severity that dengue was dangerous and caused death in this study. Another study in Indonesia supported this result that individuals considered dengue as severe and deadly disease [26]. Since dengue was one of the common infectious diseases in Indonesia, it might make respondents cautious to dengue by doing the prevention actions. During data collection, some of them mentioned that dengue could cause death if the patient did not get appropriate treatment. Respondents had moderate perception concerning benefit of practicing dengue prevention behavior. However, several of them disagreed that it would be safe to put abate into water container (14.5\%) and use mosquito coils (29.5\%). Few respondents perceived that abates were not safe particularly in water storage for drinking and cooking. They were afraid of chemical inside abate. Furthermore, few of them hesitated to put abate into water container if they did not get from health care provider. The reason of not using mosquito coils was that they were afraid of the adverse effect. Some of them revealed that they had used it and got some respiratory problem and bad smell.

Respondents had moderate perception regarding barrier of dengue prevention behavior. Few respondents had negative perception such as using mosquito coils caused bad smell (35\%), and was expensive (24.1\%). Some of them disliked the smell of mosquito coils because the smell would stay for whole day and make clothes smell. Few respondents with less income said that some of the mosquito coils were expensive. They also mentioned that cleaning water container regularly was time consuming (16.3\%) and wearing long sleeves at daytime limited movement for doing activities. Several respondents had big water container and it might need effort to clean it. Since the temperature at daytime was high in Malang, some of the respondents preferred to wear short clothes for doing daily activities.

\section{Dengue Prevention Behavior}

Only 3.2 percent of respondents had good level of dengue prevention behavior. In general, this study found that respondents practiced moderate level of dengue prevention behavior. Previous studies in Thailand $[21,26]$ revealed that respondents practiced moderate level of dengue prevention behavior. Another study in Aceh found 70.35 percent individuals practiced need improvement level of dengue prevention behavior [25]. Another study in Malang revealed that 52 percent of households had good prevention behavior [6]. The possible reason for difference might depend on the criteria to categorize towards good, moderate, or need improvement level. The criteria for categorizing respondent's behavior in this study used Benjamin Bloom taxonomy. Around 61 percent of respondents practiced moderate level of dengue prevention behavior. This might be because the majority of respondents were familiar with the prevention actions particularly $3 \mathrm{M}$ activities. Few 
respondents mentioned that they were doing such behavior because of their habit. Although they did not know certain reason for doing it, they had done the prevention actions. Moreover, every house had water container in the bathroom, may lead respondents to clean it regularly. This study found that $3 \mathrm{M}$ activities was the most common behavior done. Approximate 83 percent of respondents (83.5\%) covered water container indoors. The most second was personal protection activity such as wearing long sleeves at daytime (81.7\%). Previous study found that participants are likely to practice personal protection activity for example putting abate in the water container [16] or using mosquito nets $[27,29]$. However, a study in Laos revealed that they perform both personal protection such as use mosquito nets and $3 \mathrm{M}$ behavior such as covering water container [11]. This study showed that respondents also performed both personal protection and $3 \mathrm{M}$ activity such as covering water container and wearing long sleeves at daytime. Majority of respondents knew $3 \mathrm{M}$ and practiced it in daily life regularly such as cleaning water container in the bathroom, covering water container, or throwing discarded items. However, some of them might not do as recommended. For example, few respondents clean water container once a month or never clean it. For those who never clean containers, they expected that other family members would do. During data collection, some respondents mentioned they would not clean it by themselves because other family member always did. For plus activity of dengue prevention behavior, 15.9 percent of respondents used mosquito coils properly and 7.7 percent of them used repellent at daytime. Around 18 percent of them put abate in the water container. It was found that 15 percent of respondents wore long sleeves and 18.6 percent of respondents wore long pants or skirts. The rest of the participants practiced less properly, for example some respondents used mosquito coils and repellent at the night time. Several respondents mentioned they disliked to use mosquito coils or repellent because they worried about adverse effect and no need to use because there were rare mosquitoes flying around their house. Few respondents suggested that mosquito racket was better than mosquito coils. They also mentioned that abate was not effective in killing mosquito larva. Some of the respondents mentioned several activities that could prevent dengue besides $3 \mathrm{M}$ and plus activities such as cleaning house, garden, and environment around house, maintaining healthy life and consuming healthy or herbal food. Using mosquito racket was part of plus activities that they suggest to do because it was easy and safer. In addition, few of them said avoiding hanging clothes may be another prevention practice. This finding showed that several respondents practiced some prevention actions besides $3 \mathrm{M}$ and plus activities.

\section{CONCLUSION}

In general, respondents had moderate level of knowledge. However, they had low knowledge and need improvement level of practice regarding prevention actions particularly plus prevention activities. Therefore, this study suggests that $3 \mathrm{M}$ plus campaign should provide more information about prevention behaviour knowledge in terms of plus activities.

\section{REFERENCES}

1. Ministry of Health of Indonesia. Dengue hemorrhagic in Indonesia year 1969-2009. Buletin Jendela Epidemiologi. 2010; 2(1): 1-12.

2. Karyanti MR, Uiterwaal CS, Kusriastuti R, Hadinegoro SR, Rovers MM, Heesterbeek H, Bruijning-Verhagen P. The chang ing incidence of dengue haemorrhagic fever in Indonesia: A 45-year registry-based analysis. BMC Infectious Diseases. 2014; 14(1): 412. DOI: 10.1186/1471-2334-14-412 
3. Pratamawati DA. Mosquito larva monitoring inspector role in early alert system dengue hemorrhagic fever in Indonesia. Kesehatan Masyarakat Nasional. 2012; 6(6): 243-248. D0I: 10.21109/kesmas.v6i6.76

4. Ministry of Health of Indonesia. Profile of disease control and environmental health. dirjen pengendalian penyakit dan penyehatan lingkungan. n.d. Available from: goo.gl/Bb3GrP

5. Public Health Office of Malang. Prevalence dengue hemorrhagic fever year 2015. Pencegahan dan Pengendalian Penyakit. 2015; 3(2): 12-16.

6. Lilik Z, Rasyid HA, Hariani DR. Related between dengue fever risky behaviors with dengue hemorrhagic fever incidence in Sawojajar residents Malang city. [Bachelor thesis]. Faculty of Medicine, Malang, ID: Brawijaya University; 2010.

7. Zuhriyah L, Habibie IY, Baskoro AD. The key container of Aedes aegypti in rural and urban Malang, East Java, Indonesia. Health and the Environment Journal. 2012; 3(3): 51-8.

8. Kusriastuti R, Sutomo S. Evolution of dengue prevention and control. Dengue Bulletin. 2005; 29(1): 1-7.

9. Chandren JR, Wong LP, AbuBakar S. Practices of dengue fever prevention and the associated factors among the Orang asli in peninsular Malaysia. PLoS NegI Trop Dis. 2015; 9(8): e0003954. DOI: 10.1371/journal.pntd.0003954

10. Wong LP, Shakir SMM, Atefi N, AbuBakar S. Factors affecting dengue prevention practices: Nationwide survey of the Malaysian public. PloS one. 2015; 10(4): e0122890. DOI: 10.1371/journal.pone.0122890

11.Mayxay M, Cui W, Thammavong S, Khensakhou K, Vongxay V, Inthasoum L, Armstrong G. Dengue in peri-urban PakNgum district, Vientiane capital of Laos: A community survey on knowledge, attitudes and practices. BMC Public Health. 2013; 13(1): 13-434. DOI: 10.1186/1471-2458-13-434

12. Mohamad M, Selamat MI, Ismail Z. Factors associated with larval control practices in a Dengue outbreak prone area. Journal of Environmental and Public Health. 2014: 1-7. D0I: 10.1155/2014/459173

13. Paz-Soldán VA, Morrison AC, Lopez JJC, Lenhart A, Scott TW, Elder JP, McCall PJ. Dengue Knowledge and preventive practices in Iquitos, Peru. The American Journal of Tropical Medicine and Hygiene. 2015; 93(6): 1330-1337. DOI: 10.4269 /ajtmh.15-0096

14. Juni MH, Hayati KS, Cheng CM, Pyang GS, Samad NHBA, Abidin Z. Risk behaviour associated with dengue fever among rural population in Malaysia. International Journal of Public Health and Clinical Sciences. 2015; 2(1): 114-127.

15. Sayavong C, Chompikul J, Wongsawass S, Rattanapan C. Knowledge, attitudes and preventive behaviors related to dengue vector breeding control measures among adults in communities of Vientiane, capital of the Lao PDR. Journal of Infection and Public Health. 2015; 8(5): 466-473. D0I: 10.1016/j.jiph.2015.03.005

16. Koenraadt CJ, Tuiten W, Sithiprasasna R, Kijchalao U, Jones JW, Scott TW. Dengue knowledge and practices and their impact on Aedes aegypti populations in Kamphaeng Phet, Thailand. The American Journal of Tropical Medicine and Hygiene. 2006; 74(4): 692-700.

17. Hairi F, Ong CH, Suhaimi A, Tsung TW, Bin Anis Ahmad MA, Sundaraj C, Soe MM. A knowledge, attitude and practices (KAP) study on dengue among selected rural communities in the Kuala Kangsar district. Asia-Pacific Journal of Public Health. 2003; 15(1): 37-43. DOI: 10.1177/101053950301500107

18. Shuaib F, Todd D, Campbell-Stennett D, Ehiri J, Jolly PE. Knowledge, attitudes and practices regarding dengue infection in Westmoreland, Jamaica. The West Indian Medical Journal. 2010; 59(2): 139-141.

19. Israel Glenn D. Determining sample size. 2015. Available from: goo.gl/rA60hR

20. Linn KT. Preventive practice on dengue hemorrhagic fever among Myanmar migrant community in Samut prakan Province, Thailand [Master thesis]. Faculty Public Health, Salaya, TH, Mahidol University; 2009.

21. Sakai M. Factors related to prevention behavior against dengue hemorrhagic fever in Muang District, in Samut Sakhon, Thailand. Journal of Public Health and Development. 2007; 5(3): 55-62.

22. In Gede Suyasa Napdiwra. Association between environmental factors and behaviour with existance of dengue hemorrhagic fever (DHF) vector in primary health care South Denpasar. Ecotrophic. 2007; 3(1): 1-6.

23. Jeelani S, Sabesan S, Subramanian S. Community knowledge, awareness and preventive practices regarding dengue fever in Puducherry-South India. Public Health. 2015; 129(6): 790-796. D0I: 10.1016/j.puhe.2015.02.026 
24. Chanyasanha C, Guruge GR, Sujirarat D. Factors influencing preventive behaviors for dengue infection among housewives in colombo, Sri Lanka. Asia-Pacific Journal of Public Health. 2014; 27(1): 96-104.

DOI: $10.1177 / 1010539514545646$

25. Herlina. Preventive practice on dengue hemorrhagic fever in nanggroe aceh Darussalam province Indonesia. Master thesis. Faculty Public Health, Salaya, TH, Mahidol University; 2006.

26. Cahyo K. Study of factors affecting dengue prevention of dengue fever in family in the Village Meteseh, Semarang. Media Litbang Kesehatan. 2006; 4: 32-41.

27. Mo Wm. Dengue preventive behavior among Myanmar migrants in Mae Sot District, Tak Province, Thailand. (Master thesis). Faculty of Public Health, Salaya, TH, Mahidol University; 2011.

28. Goyal B, Goyal RC. Community thinking and acting: An evaluation of effectiveness of health talks, health exhibitions, role plays and puppet shows. International Journal of Health and Medical Sciences. 2015; 1(3): 65-69.

29. Phiri JD. Innovatively exploring the constraints and challenges faced by malaria patients in the prevention and control of malaria-Nkhata Bay Malawi. Journal of Advances in Health and Medical Sciences. 2016; 2(2): 42-53.

— This article does not have any appendix. - 